American Journal of Applied Sciences 6 (5): 882-887, 2009

ISSN 1546-9239

(C) 2009 Science Publications

\title{
Effect of Adding Dexmedetomidine versus Fentanyl to Intrathecal Bupivacaine on Spinal Block Characteristics in Gynecological Procedures: A Double Blind Controlled Study
}

\author{
${ }^{1}$ Subhi M. Al-Ghanem, ${ }^{1}$ Islam M. Massad, ${ }^{1}$ Mahmoud M. Al-Mustafa, ${ }^{1}$ Khaled R. Al-Zaben, ${ }^{1}$ Ibrahim Y. \\ Qudaisat, ${ }^{2}$ Ayman M. Qatawneh and ${ }^{3}$ Hamdi M. Abu-Ali \\ ${ }^{1}$ Department of Anesthesia and Intensive Care, Faculty of Medicine, University of Jordan, Jordan \\ ${ }^{2}$ Department of Obstetrics and Gynecology, Faculty of Medicine, University of Jordan, Jordan \\ ${ }^{3}$ Department of General Surgery, Faculty of Medicine, University of Jordan, Jordan
}

\begin{abstract}
Problem statement: The purpose of this study was to evaluate the onset and duration of sensory and motor block as well as operative analgesia and adverse effects of Dex Metedo Midine (DXM) or fentanyl given intrathecally with plain 0.5\% bupivacaine for spinal anesthesia. Approach: seventy six patients classified as American Society of Anesthesiologists (ASA) status I, II and III scheduled for vaginal hysterectomy, vaginal wall repair and tension free vaginal tape were prospectively studied. Patients were randomly allocated to receive intrathecally either $10 \mathrm{mg}$ isobaric bupivacaine plus $5 \mu \mathrm{g}$ dexmetedomidine (group D $\mathrm{n}=38$ ) or $10 \mathrm{mg}$ isobaric bupivacaine plus $25 \mathrm{mg}$ fentanyl (group F n = 38), the onset time to reach peak sensory and motor level, the regression time for sensory and motor block, hemodynamic changes, and side effects were recorded. Results: Patients in group D had significant longer sensory and motor block times than patients in group F. the mean time of sensory regression to $\mathrm{S} 1$ was $274 \pm 73 \mathrm{~min}$ in group $\mathrm{D}$ and $179 \pm 47 \mathrm{~min}$ in group $\mathrm{F}(\mathrm{P}<0.001)$. The regression time of motor block to reach modified Bromage 0 was $240 \pm 60$ min in group D and $155 \pm 46$ min in group $\mathrm{F}(\mathrm{P}<0.001)$. The onset times to reach $\mathrm{T} 10$ dermatome and to reach peak sensory level as well as onset time to reach modified Bromage 3 motor block were not significantly different between the two groups. Conclusion: In women undergoing vaginal reconstructive surgery under spinal analgesia, $10 \mathrm{mg}$ plain bupivacaine supplemented with $5 \mu \mathrm{g}$ dexmetedomidine produces prolonged motor and sensory block compared with $25 \mu \mathrm{g}$ fentanyl.
\end{abstract}

Keywords: Dexmetedomidine, fentanyl, bupivacaine, spinal anesthesia

\section{INTRODUCTION}

Vaginal surgery including vaginal hysterectomy, tension free vaginal tape and vaginal repair are often done under regional anesthesia. Surgery on the uterus and other genital organs performed under epidural or spinal block is often accompanied by visceral pain, nausea and vomiting ${ }^{[1,2]}$. Fentanyl in various doses $(10$, $20,30,40 \mu \mathrm{g}$ ) when added to spinal bupivacaine increase the duration of analgesia and reduce intraoperative nausea and vomiting ${ }^{[3]}$. DXM is an $\alpha 2-$ adrenoreceptor agonist that is approved as an intravenous sedative and coanalgesic drug. Its use is often associated a decrease in heart rate and blood pressure ${ }^{[4]}$. Intrathecal and epidural characteristics of DXM were studied in animals ${ }^{[5,6]}$. Most of the clinical studies about intrathecal $\alpha 2$ adrenoreceptor agonist are related to clonidine. There is little in the literature about the use of intrathecal DXM with local anesthesia in humans. Kanazi et al. ${ }^{[7]}$ found that $3 \mu \mathrm{g}$ DXM and 30 $\mu \mathrm{g}$ clonidine are equipotent intrathecally when added to bupivacaine in patients undergoing urology procedures. The same author found that DXM and clonidine produced significant short onset of sensory and motor block as well as significantly longer duration of sensory and motor block than bupivacaine alone without serious side effects. The aim of this study was to compare the effect of DXM $5 \mu \mathrm{g}$ versus fentanyl $25 \mu \mathrm{g}$ on intraoperative analgesia and the duration of sensory motor block when added to $10 \mathrm{mg}$ intrathecal plain bupvacaine.

\section{MATERIALS AND METHODS}

The protocol of the study was approved by the scientific search committee of the medical college and written consent was obtained preoperatively. Seventy eight patients (ASA I-III) scheduled for tension-free

Corresponding Author: Subhi M. Al-Ghanem, Department of Anesthesia and Intensive Care, Faculty of Medicine, University of Jordan 
vaginal tape, vaginal wall repair, and vaginal hysterectomy under spinal anesthesia were included in this prospective randomized, double blinded study. Patients with uncontrolled, labile hypertension or patients with allergy to the study drugs were excluded from the study. Patients received no premedication, and upon arrival of patients into the operating room, ECG, pulse oximetry, and non invasive blood pressure were monitored. Following infusion of $500 \mathrm{~mL}$ Lactated Ringers solution and while the patient in the sitting position lumber puncture was performed at L3-L4 level through a midline approach using a 25-gauge Quincke spinal needle (B Braun medical, Germany). Using a computer generated random numbers, patients were allocated into 2 groups and group D received isobaric bupivacaine $10 \mathrm{mg}$ and $5 \mu \mathrm{g}$ DXM in $2.5 \mathrm{mLs}$. Group F received $10 \mathrm{mg}$ isobaric bupivacaine and $25 \mu \mathrm{g}$ fenatnyl into $2.5 \mathrm{~mL}$. DXM (precedex $100 \mu \mathrm{g} \mathrm{mL} \mathrm{mL}^{-1}$ Abbott laboratory) were diluted in preservative free normal saline. After intrathecal injection, patients were positioned in lithotomy position and oxygen $2 \mathrm{Lmin}^{-1}$ was given through a face mask. The doctor anesthetist performing the block was blinded to the study drug and recorded the intraoperative data. Vital signs were recorded at 5 min interval intraoperatively until the end of surgery. In the Post Anesthesia Care Unit (PACU), vital signs were recorded every $15 \mathrm{~min}$. The sensory block level was assessed by cold alcohol swap along the midclavicular line bilaterally. The motor block was assessed according to the modified Bromage scale ${ }^{[8]}$ : Bromage 0, the patient is able to move the hip, knee and ankle; Bromage 1, the patient is unable to move the hip but is able to move the knee and ankle; Bromage 2, the patient is unable to move the hip and knee but able to move the ankle; Bromage 3, the patient is unable to move the hip, knee and ankle. The times to reach T10 dermatome sensory block, peak sensory level and Bromage 3 motor block were recorded before surgery. The regression time for sensory and motor block were recorded in PACU. All durations were calculated considering the time of spinal injection as time zero. Patients were discharged from the PACU after sensory regression to $\mathrm{S} 1$ dermatome and Bromage 0 . Assessment of pain intraoperatively and in PACU was done using visual analogue pain scale between $0-10(0$ $=$ no pain, $10=$ the most severe pain). Intraoperative nausea, vomiting, pruritus, additive analgesia and sedation were recorded. The following sedation scale was used: $0=$ no sedation, $1=$ mild sedation, $2=$ moderate sedation, $\quad 3=$ severe sedation. Hypotension was defined as a decrease in systolic blood pressure $>$ $30 \%$ of the baseline value or systolic blood pressure < $100 \mathrm{~mm} \mathrm{Hg}$, hypotension was treated with intravenous blouses of $6 \mathrm{mg}$ ephedrine and crystalloid fluids. Bradycardia was defined as a pulse rate of $<50$ beat/ min and was treated with boluses of $0.3-0.5 \mathrm{mg}$ atropine.

Statistical methods: Statistical analysis was done using statgraphics centurion XV (Statpoint, Herdon, VirginiaUSA). Data was expressed as either mean and standard deviation or numbers and percentages. The demographic data of patients were studied for each of the three groups. Continues covariates (Age, BMI, gage and duration of surgery were compared using analysis of variance ANOVA. For categorical covariates (sex, ASA class, nausea/ vomiting, hypotension, bradycardia, use of ephedrine, use of additive analgesia, the use of atropine and type of surgery). The comparison was studied using chi-squared test or the Fisher's exact test as appropriate, with the $\mathrm{p}$ value reported at the $95 \%$ confidence interval. The level of significance used was $\mathrm{p}=0.05$.

To calculate the sample size, a power analysis of ( $\alpha$ $=0.05$ and $\beta=0.90$ ) showed that 30 patients per study group were needed to detect an increase of $30 \mathrm{~min}$ difference between the median duration of spinal sensory block between the groups.

\section{RESULTS}

All patients $(n=76)$ completed the study; there was no statistical difference in patients' demographics or the duration and type of surgery as shown in Table 1. The onset time of sensory block to reach T10 dermatome was 7.5 $\pm 7.4 \mathrm{~min}$. for Group D and 7.4 \pm 3.3 min. for Group $F(p=0.95)$. The time to reach the maximal sensory block was $19.34+2.87 \mathrm{~min}$. for group $\mathrm{D}$ and 18.39+2.46 min. for Group F ( $\mathrm{p}=0.126)$ The onset time of modified Bromage 3 motor block was also not different between group D and F; 14.4+6.7 and $14.3+5.7 \mathrm{~min}$. respectively $(\mathrm{P}=0.93)$. The regression time to reach modified Bromage 0 in Group D ( 240+64 min. ) was significantly longer than that for group $\mathrm{F}$ (155+46 min. ), $\mathrm{p}<0.001$. The time reach $\mathrm{S} 1$ segment was significantly longer in group D $(274.8+73.4 \mathrm{~min}$. than in group $\mathrm{F}(179.5+47.4$ min. $)(\mathrm{P}<0.001)$ Table 2. The peak sensory level was T6 (T4-T9) in group D and T6 (T3-T8) in group F, without significant difference between the group $(\mathrm{p}=0.88)$.

The mean values of mean arterial blood pressure and heart rate were comparable among the 2 groups (figures 1 and 2). The sedation score was between 0 and 1 in both groups. Side effects of spinal block are shown in Table 3. The overall side effects were significantly more in group $\mathrm{F}$ than in group $\mathrm{D}(\mathrm{P}<0.002)$. 
Am. J. Applied Sci., 6 (5): 882-887, 2009

Table 1: Patients demographics. Values are mean \pm SD. BMI $=$ body mass index. TVT= tension free vaginal tape

\begin{tabular}{lll}
\hline Variable & Group D $(\mathrm{n}=38)$ & Group F $(\mathrm{n}=38)$ \\
\hline Age (yr) & $49.0 \pm 10.9$ & $49.6 \pm 11.6$ \\
BMI & $29.1 \pm 6.1$ & $31.3 \pm 6.2$ \\
ASA I, II, III & $22,16,0$ & $16,17,5$ \\
TVT, vaginal repair, & $18,19,4$ & $22,18,5$ \\
vaginal hysterectomy & & \\
Duration of surgery (min) & $51.6 \pm 26.8$ & $59.0 \pm 25.7$ \\
Need for ephedrine & 4 & 8 \\
Dose of ephedrine (mg) & $10.5 \pm 1.73$ & $12.37 \pm 10.07$ \\
Need for atropine & 1 & 2 \\
\hline
\end{tabular}

Table 2: Characteristics of spinal block, data are shown as mean $\pm \mathrm{SD}$. The maximal sensory block level is given as median (range)

\begin{tabular}{llll}
\hline Variable & $\begin{array}{l}\text { Group D } \\
(\mathrm{n}=38)\end{array}$ & $\begin{array}{l}\text { Group F } \\
(\mathrm{n}=38)\end{array}$ & P value \\
\hline $\begin{array}{l}\text { Peak sensory } \\
\text { block level }\end{array}$ & T6 (T4-T9) & T6 (T3-T8) & 0.88 \\
$\begin{array}{l}\text { Time to reach T10 sensory } \\
\text { block level (min) }\end{array}$ & $7.5 \pm 7.4$ & $7.4 \pm 3.3$ & 0.95 \\
$\begin{array}{l}\text { Time to reach peak sensory) } \\
\text { Time to reach Bromage 3 }\end{array}$ & $19.34 \pm 2.87$ & $18.39 \pm 2.46$ & 0.126 \\
motor block (min) & $14.3 \pm 5.7$ & 0.932 \\
$\begin{array}{l}\text { Regression time to S1 } \\
\text { dermatome level (min) }\end{array}$ & $274.8 \pm 73.4$ & $179.5 \pm 47.4<0.001$ \\
$\begin{array}{l}\text { Regression time to } \\
\text { Bromage 0 (min) }\end{array}$ & $240 \pm 64$ & $155 \pm 46$ & $<0.001$ \\
\end{tabular}

Table 3: Adverse effects of spinal block. Values are numbers (\%)

\begin{tabular}{llll}
\hline Side Effect & $\begin{array}{l}\text { Group D } \\
(\mathrm{n}=38)\end{array}$ & $\begin{array}{l}\text { Group F } \\
(\mathrm{n}=38)\end{array}$ & P value \\
\hline Nausea/ Vomiting & $2(5)$ & $4(10)$ & 0.401 \\
Pruritus & 0 & $5(13)$ & 0.169 \\
Hypotension & $4(10)$ & $9(24)$ & 0.242 \\
Bradycardia & $2(5)$ & $3(8)$ & 0.649 \\
$\begin{array}{l}\text { Need for intraoperative } \\
\text { analgesia }\end{array}$ & $3(8)$ & $2(5)$ & 0.169 \\
Total & $11(29)$ & $23(60)$ & 0.021 \\
\hline
\end{tabular}

Hypotension was mild to moderate in both groups except one patient in group $\mathrm{F}$, who had a blood pressure less than $90 \mathrm{mmHg}$, and required $36 \mathrm{mg}$ ephedrine to restore his blood pressure. Pruritis was absent in group $\mathrm{D}$, but was present in 5 patients in group $\mathrm{F}, \mathrm{p}=0.169$. Nausea and vomiting were more in group F, than group $\mathrm{D}$, but it did not reach statistical difference. Five patients (three in group $\mathrm{D}$, and two in group F), required intraoperative analgesia. Two patients in group F complained of postdural puncture headache which was treated by hydration and simple analgesia.

\section{DISCUSSION}

Present results in this study showed that the supplementation of spinal bupivacaine with $5 \mu \mathrm{g}$ DXM significantly prolonged both sensory and motor block compared with intrathecal $25 \mu \mathrm{g}$ fentanyl and bupivacaine in vaginal reconstructive surgery.

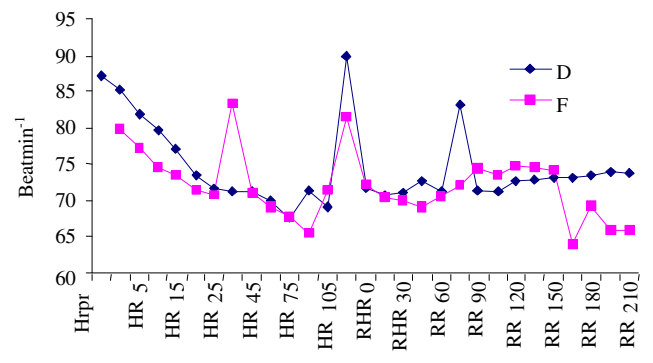

Time (min)

Fig. 1: Heart rate (HR). Values are the means \pm SD

Hrpre $=$ heart rate before spinal block

$\mathrm{R} H \mathrm{HR}=$ heart rate in the post anesthesia recovery room

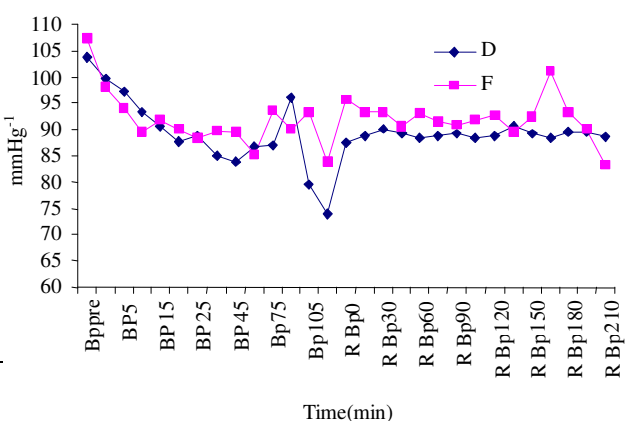

Fig. 2: Mean arterial blood pressure (MAP). Values are the means \pm SD

Bppre $=$ blood pressure before spinal block

$\mathrm{R} \mathrm{Bp}=$ mean arterial blood pressure in the post anesthesia recovery room

Both fentanyl and DXM improved the quality of intraoperative analgesia and diminished the risk of supplementation of general anesthesia. Fentanyl is a lipophillic $\mu$-receptors agonist opioid. Intrathecally, fentanyl exerts its effect by combining with opioid receptors in the dorsal horn of spinal cord and may have a supra spinal spread and action ${ }^{[9,10]}$. Pain is frequently encountered during surgery on the female genital organs under spinal local anesthetics, intrathecal fentanyl when added to spinal local anesthetics reduces significantly visceral and somatic pain and this analgesic effect has been proved by many studies ${ }^{[11-14]}$.

Intrathecal fentanyl prolongs the duration of spinal anesthesia produced by bupivacaine and lignocaine and this effect has been shown in obstetric and non-obstetric patients undergoing various surgeries ${ }^{[15,16]}$. The prolongation of the duration of spinal analgesia produced by intrathecal fentanyl is not a dose related. Seewal et al..$^{[3]}$ found a significant improvement in the duration and quality of analgesia produced by intrathecal fentanyl and bupivacaine compared to 
intrathecal bupivacaine alone, meanwhile, the author found no further increase in the duration of analgesia when the dose of fentanyl was increased from $10 \mu \mathrm{g}$ to 20 , 30, or $40 \mu \mathrm{g}$. Kuusniemi et al. $\left.{ }^{[15}\right]$ reported that different durations of spinal anesthesia were related to different doses of spinal bupivacaine supplemented with $25 \mu \mathrm{g}$ fentanyl in patients undergoing urology procedures. Hamber et al. ${ }^{[17]}$ in a review article found that a dose of 20-30 $\mu \mathrm{g}$ fentanyl as adjunct to spinal anesthesia produces faster block onset time, improved intraoperative analgesia and decrease incidence of intraoperative nausea and vomiting in obstetric patients. In non obstetric patients studies demonstrated that adose of $25 \mu \mathrm{g}$ fentanyl for supplementation of spinal anesthesia produces the excellent quality of perioperative analgesia ${ }^{[18-20]}$. In present study and based on the above studies findings, fentanyl in a dose of 25 $\mu \mathrm{g}$ was used for supplementation of spinal bupivacaine. DXM is a highly selective $\alpha 2$-adrenoreceptor agonist approved as intravenous sedative and adjuvant to anesthesia. DXM when used intravenously during anesthesia reduces opioid and inhalational anesthetics requirements ${ }^{[21,22]}$. Compared with clonidine a $\alpha 2$ adrenoreceptor agonist, the affinity of DXM to $\alpha 2$ receptors has been reported to be 10 times more than clonidine $^{[23]}$, moreover, Kalso et al. ${ }^{[5]}$ and Post et al. ${ }^{[24]}$ reported a 1:10 dose ratio between intrathecal DXM and clonidine in animals. Clinical studies in surgical patients showed that intrathecal clonidine increases the duration of sensory and motor spinal block when added to spinal local anesthetics and this effect of clonidine is dose-dependent ${ }^{[25-27]}$, and doses of more than $75 \mu \mathrm{g}$ intrathecal clonidine is accompanied by excessive sedation, hypotension and bradycardia. De kock et al. ${ }^{[28]}$ recommended a dose of $15-45 \mu \mathrm{g}$ clonidine for supplementation of spinal anesthesia since this dose effectively prolongs the duration of spinal block with minimal sedation and side effects. The clinical studies about the use of intrathecal DXM in surgical patients are scarce in the literature. Kanazi et al. ${ }^{[7]}$ found that $3 \mu \mathrm{g}$ DXM or $30 \mu \mathrm{g}$ clonidine added to $13 \mathrm{mg}$ spinal bupivacaine produced the same duration of sensory and motor block with minimal side effects in urologic surgical patients. From Kanazi study and animal studies, we assumed that 3-5 $\mu \mathrm{g}$ DXM would be equipotent to $30-45 \mu \mathrm{g}$ clonidine when used for supplementation of spinal bupivaciane.

Intrathecal DXM when combined with spinal bupivacaine prolongs the sensory block by depressing the release of C-fibers transmitters and by hyperpolarization of pos-synaptic dorsal horn neurons ${ }^{[29-33]}$. Motor block prolongation by $\alpha 2-$ adrenoreceptor agonists may result from binding these agonists to motor neurons in the dorsal horn of the spinal cord ${ }^{[34,35]}$. Intrathecal $\alpha 2$-receptor agonists have been found to have antinoniceptive action for both somatic and visceral pain ${ }^{[36,37]}$. In this study, the intrathecal DXM and bupivacaine block has resulted in significantly less side effects than intrathecal fentanyl bupivacaine block.

The most significant side effects reported about the use of intrathecal $\alpha 2$ adrenoreceptor agonists are bradycardia and hypotension, in present study, these side effects were not significant probably because we used small dose of intrathecal DXM which was confirmed by the findings of Kanazi report. In present study hypotension was more in the fentanyl group than in the DXM group, but it did not reach a significant difference. Meanwhile, hypotension occurred 25-30 min after spinal injection. 2 patients in the DXM group and one patient in fentanyl group had mild episodes of hypotension in the PACU. Pruritus after intrathecal fentanyl is reported to be $40-70 \%$ but it was only $13 \%$ in present study which can be explained by the fact that pruritus is a benign subjective symptom which is under reporting and usually need no treatment.

\section{CONCLUSION}

Intrathecal DXM supplementation of spinal block seems to be a good alternative to intrathecal fentanyl since it produces prolonged sensory block, and it is evident that this type of block may be more suitable for major surgeries on the abdomen and lower extremities. The dose of DXM $(5 \mu \mathrm{g})$ used in present study was suitable and comparable to clonidine $45 \mu \mathrm{g}$ as suggested by De kock et al. ${ }^{[28]}$. Intrathecal dose of DXM use in present study needs further clinical studies to prove its efficacy and safety and to be considered the suitable dose of DXM for supplementation of spinal local anesthetics. A drawback of DXM supplemented spinal block characteristics in this study is the increase in the duration of motor block which may not suit short term surgical procedures or ambulatory surgery.

In conclusion, $5 \mu \mathrm{g}$ DXM seems to be an attractive alternative as adjuvant to spinal bupivacaine in surgical procedures especially in those that need quite long time with minimal side effects and excellent quality of spinal analgesia.

\section{REFERENCE}

1. Alahuhta S, Kangas-Saarela $\mathrm{T}$, Hollmen AL, Edstrom HH. Visceral pain during caesarean section under spinal and epidural anesthesia with bupivacaine. Acta Anesthesiol Scand 1990; 34: 95-8. DOI:10.1111/j.1399-6576.2004.00580.x 
2. Pedersen H, Santos CA, Stinberg ES, et al. Incidence of visceral pain during cesarean section: the effect of varying doses of spinal bupivacaine. Anesth Analg 1990; 69: 46-9. http://www.ncbi.nlm.nih.gov/pubmed/2742167

3. Seewal R, Shende D, Kashyap L, Mohan V. Effect of addition of various doses of fentanyl intrathecally to $0.5 \%$ hyperbaric bupivacaine on perioperative analgesia and subarachnoid-block characteristics in lower abdominal surgery: a doseresponse study. Reg Anesth Pain Med. 2007 Jan-Feb; 32(1): 20-6.

http://www.ncbi.nlm.nih.gov/pubmed/17196488

4. Venn RM, Grounds RM: Comparison between dexmedetomidine and propofol for sedation in the intensive care unit: patient and clinician perceptions. $\mathrm{Br} \mathrm{J}$ Anaesth 87: 684, 2001 http://www.ncbi.nlm.nih.gov/pubmed/11878517

5. Kalso E, Poyhia R, Rosemberg P. Spinal antinociceptive by dexmedetomidine, a highly selective $\alpha 2$-adrenergic agonist. Pharmacol Toxicol 1991; 68: http://www.ncbi.nlm.nih.gov/pubmed/1677190

6. Savola M, Woodley J, Kending J, Maze M. Alpha2B adrenoreceptor activation inhibits nociceptor response in the spinal cord of the neonatal rat. Eur J Pharmacol 1990; 183: 740. doi:10.1016/0014-2999(91)90055-U

7. G. E. Kanazi, M. T. Aouad, S. I. Jabbour- Khoury, M.D. Al Jazzar, M. M. Alameddine, R. AlYaman, M. Bulbul and A. S. Baraka. Effect of lowdose dexmedetomidine or clonidine on the characteristics of bupivacaine spinal block. Acta Anesthesiol Scand 2006; 50: 222-117. DOI : 10.1111/j.1399-6576.2006.00919.x

8. Bromage PR. A comparison of the hydrochloride and carbon dioxide salts of lidocaine and prilocaine in epidural analgesia. Acta Anesthesiol Scand 1965; 16: 55-69. http://www.ncbi.nlm.nih.gov/pubmed/5322004

9. Shende D, Cooper GM, Bowden MI. The influence of intrathecal fentanyl on the characteristics of subarachnoid block for caesarean section. Anaesthesia 1998; 79: 702-710. DOI : 10.1046/j.1365-2044.1998.329-az0482.x

10. Choi Dw, Ahn HJ, Kim MH. Bupivacaine-sparing effect of fentanyl in spinal anesthesia for Cesarean delivery. Reg Anesth Pain Med 2000; 25: 240-245. http://www.ncbi.nlm.nih.gov/pubmed/10834777

11. Omote K, Kawamata M, Iwasaki H, Namiki A. Effects of morphine on neuronal and behavioral response to visceral and somatic nociception at the level of spinal cord. Acta Anesthesiol Scand 1994; 38:514-7.

http://www.ncbi.nlm.nih.gov/pubmed/7941948?do $\mathrm{pt}=\mathrm{Abstract}$
12. Danzebrink RM, Gebhart GF. Antinocieptive effects of intrathecal adrenoceptors agonists in a rat model of visceral nociception. J Pharmacol Exp Ther 1990; 253: 698-705. http://www.ncbi.nlm.nih.gov/pubmed/1971018

13. Hunt Co, Naulty JS, Bader AM, et al. Perioperative analgesia with subarachnoid fentanyl-bupivacaine for cesarean delivery. Anesthesiology 1989; 71: 535-40. http://www.ncbi.nlm.nih.gov/pubmed/2679237

14. Courtney MA, Bader AM, Hartwell et al. Perioperative analgesia with subarachnoid sufentanil administration. Reg Anesth 1992; 17: 274-8 http://www.ncbi.nlm.nih.gov/pubmed/1419940

15. Kuusniemi KS, Pihlajamaki KK, Pitkanen MT, Helenius HY, Kirvela OA. The use of bupivacaine and fentanyl for spinal anesthesia for urologic surgery. Anesth Analg 2000; 91: 14521456.

http://www.ncbi.nlm.nih.gov/pubmed/11093999

16. Palmer CM, Voulgaropoulos D, ASlves D. Subarachnoid fentanyl augments lidocaine spinal anesthesia for Cesarean delivery. Region Anesth Pain Med 1995; 20: 389-394. http://www.ncbi.nlm.nih.gov/pubmed/8519715

17.Elizabeth A. Hamber, M.D., and Christopher M. Viscomi M.D. Intrathecal lipophilic opioids as adjuncts to surgical spinal anesthesia. Regional anesthesia and pain medicine 24(3): 255-263, 1999 http://www.ncbi.nlm.nih.gov/pubmed/10338179

18. Vaghadia H, McLeod DH, Mitchell GW, Merrick PM, Chilvers CR. Small-dose hypobaric lidocainefentanyl spinal anesthesia for short duration outpatient labaroscopy. II. Optimal fentanyl dose. Anesth Analg 1997: 84: 65-70. http://www.ncbi.nlm.nih.gov/pubmed/8989000

19. Liu S, Chiu AA, Carpenter RL, Mulroy MF, Allen HW, Neal JM, Pollock JE. Fentanyl prolongs lidocaine spinal anesthesia without prolonging recovery. Anesth Analg

1995: 80: 730-734. http://www.ncbi.nlm.nih.gov/pubmed/7893026

20.Singh H, Ynag J, Thornton K, Giesecke AH. Intrathecal fentanyl prolongs sensory bupivacaine spinal block. Can J Anesth 1995: 42(11): 987-991. http://www.ncbi.nlm.nih.gov/pubmed/8590509

21. Fragen RJ, Fitzgerald PC. Effect of dexmedetomidine on the minimum alveolar concentration (MAC) of sevoflurane in adults age 55-70 years. J Clin Anesth 1999; 11: 466-70 http://www.ncbi.nlm.nih.gov/pubmed/10526824 
22. Martin E, Ramsay G, Mantz J, Sum-Ping ST. the role of the alpha2-adrenreceptor agonist dexmedetomidine in post-surgical sedation in the intensive care unit. J intensive Care Med 2000; 18: 29-34.

DOI: $10.1177 / 0885066602239122$

23. Post C, Gordh $\mathrm{T}$, Minor $\mathrm{G}$, Archer $\mathrm{T}$, Freedman J. Antinociceptive effects and spinal cord tissue concentrations after intrathecal injection of guanfacine or clonidine into rats. Anesth Analg 1987; 66: 317-24 http://www.ncbi.nlm.nih.gov/pubmed/11571417

24. Bonnet F, Burn-Buisson V, Saada M, et al. Dose-related prolongation of hyperbaric tetracaine spinal anesthesia by clonidine in humans. Anesth Analg 1989; 68: 619-22. http://www.ncbi.nlm.nih.gov/pubmed/2719293

25. Racle JP, Benkhadra A, Poy JY, Gleizal B. Prolongation of isobaric bupivacaine spinal anesthesia with epinephrine and clonidine for hip surgery in the elderly. Anesth Analg 1987;66:442-6.

http://www.ncbi.nlm.nih.gov/pubmed/3555164

26. Niemi L. effects of intrathecal clonidine on duration of bupivacaine spinal anesthesia, hemodynamics, and postoperative analgesia in patients undergoing knee arthroscopy. Acta Anaesthesiol Scand 1994; 38: 724-8. http://www.ncbi.nlm.nih.gov/pubmed/7839785

27. Marc De Kock, M.D., Ph.D., Philipe Gautier, M.D., Luc Fanard, M.D., Jean Luc Hody, M.D., Patricia Lavand'homme, M.D., Ph.D. Intrathecal Ropivacaine and clonidine for ambulatory Knee arthroscopy. A doseresponse study. Anesthesiology 2001; 94: 574-8. http://www.ncbi.nlm.nih.gov/pubmed/11379675

28. Eisanach JC, De Kock M, Klimscha W. $\alpha 2$ adrenergic agonists for regional anesthesia. Anesthesiology 1996: 85: 655-74 http://www.ncbi.nlm.nih.gov/pubmed/8853097
29. Lawhead RG, Blaxall HS, Bylund BD. Alpha$2 \mathrm{~A}$ is the predominant $\alpha-2$ adrenergic receptor subtype in human spinal cord. Anesthesiology 1992;77:983-91. http://www.ncbi.nlm.nih.gov/pubmed/1359811

30. Smith MS, Schumbra UB, Wilson KH et al. Alpha 2 adrenergic receptor in human spinal cord: specific localized expression of mRNA encoding alpha-2 adrenergic receptor subtypes at four distinct levels. Brain Res 1995; 34: 109-17 http://www.ncbi.nlm.nih.gov/pubmed/8750866

31. Fairbanke CA, Wilcox GL. Spinal antinociceptive synergism between morphine and clonidine persists in mice made acutely or chronically tolerant to morphine. J Pharmacol Exp Ther 1999; 288: 1107-16 http://www.ncbi.nlm.nih.gov/pubmed/1002784 8

32. Yaksh TL. Pharmacology of spinal adrenergic systems which modulate spinal nociceptive processing. Pharmacol Biochem Behav 1985; 22:845-58 http://www.ncbi.nlm.nih.gov/pubmed/2861606

33. Smith C, Birnbaum G, Carter JL, Greenstein J, Lublin FD. Tizanidine treatment of spasticity caused by multiple sclerosis. Neurology 1994; 44(9):34-43.

http://www.ncbi.nlm.nih.gov/pubmed/7970009

34. Harada Y, Nishioka K, Kitahata LM, et al. Visceral antinociceptive effects of spinal clonidine combined with morphine, enkephalin, or U50, 488H. Anesthesiology 1995;83:344-52

http://www.ncbi.nlm.nih.gov/pubmed/7631957

35. Yaksh TL, Reddy SVR. Studies in primate on the analgesic effects associated with intrathecal actions of opiates, $\alpha$-adrenergic agonists, and baclofen. Anesthesiology 1981; 54:451-67

http://www.ncbi.nlm.nih.gov/pubmed/6112935 